(2) OPEN ACCESS

\title{
First trimester employment, working conditions and preterm birth: a prospective population-based cohort study
}

\author{
Tanja Vrijkotte (10, ${ }^{1}$ Teus Brand, ${ }^{2}$ Gouke Bonsel ${ }^{3,4}$
}

1 Department of Public and Occupational Health, Amsterdam Public Health Research Institute, Amsterdam UMC, University of Amsterdam, Amsterdam, Netherlands ${ }^{2}$ Netherlands Center for Occupational Diseases, Coronel Institute, Amsterdam UMC, University of Amsterdam, Amsterdam, Netherlands ${ }^{3}$ Department of Public Health, Erasmus Medical Center, Rotterdam, Netherlands ${ }^{4}$ EuroQol Research Foundation, Rotterdam, Netherlands

\section{Correspondence to}

Dr Tanja Vrijkotte, University of Amsterdam, Amsterdam, NoordHolland, Netherlands; t.vrijkotte@amsterdamumc.nl

Received 20 September 2020 Revised 14 December 2020 Accepted 5 January 2021 Published Online First 24 February 2021

\begin{abstract}
Objectives To explore the association between working conditions during first trimester and total preterm birth (PTB), and subtypes: spontaneous PTB and iatrogenic PTB, additionally to explore the role of hypertension.

Methods Pregnant women from the Amsterdam Born Children and their Development study, filled out a questionnaire between January 2003 and March 2004, two weeks after first prenatal screening (singleton liveborn, $\mathrm{n}=7561$ ). Working conditions were working hours/week, standing/walking hours/week, physical work load and job strain.
\end{abstract}

Results Prolonged standing/walking during first trimester was associated with an increased risk for total PTB (OR=1.5; 95\% Cl 1.0-2.3, after adjustments). Other working conditions were not related to total PTB. The separation into spontaneous and iatrogenic PTB revealed that standing/walking was associated with iatrogenic PTB only (OR=2.09; 95\% Cl 1.00-4.97). The highest risk was found for the combination of a long workweek with high physical work load (OR=3.42; 95\% Cl 1.04-8.21). Hypertension did not mediate these associations; however, stratified analysis revealed that high physical work load was only related to iatrogenic PTB when pregnancy-induced hypertension was present $(O R=6.44$; 95\% Cl 1.21-29.76).

Conclusion This study provides evidence that high physically demanding work is associated with an increased risk for iatrogenic PTB and not with spontaneous PTB. Pregnancy-induced hypertension may play a role: when present, high physical work load leads to a more severe outcome.

\section{INTRODUCTION}

Preterm birth (PTB) is a principal adverse outcome of perinatal care, associated with infant mortality and subsequent morbidity. ${ }^{1}$ In the last decades, the prevalence of PTB slightly decreased, ${ }^{2}{ }^{3}$ while neonatal outcome in general has improved considerably. However, there is room for considerable improvement of PTB, even if we account for some iatrogenic increase. ${ }^{3}$ Risk factors for spontaneous PTB are maternal factors (including pre-existent hypertension), obstetric factors (including placental dynamics) and social factors, which include workrelated factors. ${ }^{4-6}$ Although work in general is associated with better outcomes most likely through indirect pathways ${ }^{7}$ or by selection of women with better health in employed jobs known as the

\section{Key messages}

What is already known about this subject?

- Literature suggests that high physical work load, long standing/walking hours and high job strain increase the risk of preterm birth (PTB), but evidence is inconclusive.

- There is no information on work-exposure risks for iatrogenic versus spontaneous PTB separately.

- The role of hypertensive disorders, as most important pregnancy complicating disease in developed countries, in the association between these work-related factors and PTB is unknown.

\section{What are the new findings?}

- High physical work load, and work involving more than 30 hours/week standing or walking, both were associated with a higher risk for iatrogenic PTB, but not with spontaneous PTB.

- The effect of high physical work load and a long workweek was additive; the combined risk showed the highest impact on iatrogenic PTB.

- High physical work load was only related to iatrogenic PTB if pregnancy-induced hypertension was also present.

How might this impact on policy or clinical practice in the foreseeable future?

- These results can guide health professionals' recommendations for pregnant workers combining job burden assessment with blood pressure monitoring if physical work load is high.

'healthy worker effect', ${ }^{8}$ specific working conditions are potential risk factors for PTB through direct, biological pathways. An increased risk from long working hours, ${ }^{9-11}$ high physical work load, ${ }^{12-14}$ prolonged standing ${ }^{10}$ and psychosocial job strain ${ }^{10}$ has been suggested, but results are not unequivocal. $^{12}$ 14-16

So far, six reviews have been conducted, four focusing on high physical work load, long working hours and prolonged standing and one on lifting. ${ }^{9}{ }^{17-21}$ These studies concluded that working conditions were associated with increased risk for preterm delivery, but the effects were small to moderate in these studies (pooled estimates RR $<1.3$ ). One recent meta-analysis confirmed the 
result with respect to extended working hours ( $>40$ hours/ week). ${ }^{9}$ To the best of our knowledge, job strain has only been considered in one critical review on psychosocial characteristics of work, which showed a modest but inconclusive association between job strain and PTB. ${ }^{22}$

Differences in research designs and definitions and measurements of work-related factors may account for inconsistent observations. First, frequently physical work load and working hours are considered as independent exposures. However, interaction may be assumed as heavy work load can be expected to be more detrimental under fulltime rather than part-time working conditions. Second, most studies combine spontaneous and iatrogenic (medically indicated) PTB into one outcome measure, while the pathophysiological mechanism only partially overlaps. ${ }^{523} 24$ Working conditions could thus be related differently to these types of PTB. Additionally, hypertension during pregnancy, a driver of iatrogenic PTB, could be a mediator or modifier in the relation between work and PTB. The positive association between job strain and blood pressure is consistently reported in the working population, ${ }^{25}$ and also in pregnant women. ${ }^{26}$ Finally, so far, focus is on physical work load, while only a few studies looked at self-rated job strain, defined as high job demands in combination with low job control, as a potential independent contributor to adverse outcomes, like PTB. ${ }^{27}$

The purpose of this empirical study was to explore the association between —on the one hand-the exposure of employment acknowledging different pathways via working conditions like weekly working hours, hours standing or walking, physically demanding work and psychosocial job strain, and-on the other hand - the outcome PTB, both total and subdivided into spontaneous and iatrogenic PTB. In addition, the complex role of pregnancy-induced hypertension (PIH) was explored by testing its mediating as well as its moderating role. Evidence for mediation would mean that heavy working conditions lead to PIH and subsequently to PTB. Moderation would mean that PIH acts as a risk enhancer, when present, heavy working conditions would to lead to increased risk for PTB. Shedding some light on this mechanism is important as PIH is the most important single clinical entity responsible for poor neonatal outcome in modern society and in particular in that condition iatrogenic PTB is often applied, to prevent worse outcome (fetal death) at later stage, which still often involves spontaneous PTB.

An unselected urban cohort of pregnant women was studies where work-related factors were measured prospectively at the end of the first trimester. ${ }^{28}$ We hypothesised that ${ }^{1}$ heavy working conditions are associated differently with the subtypes of PTB, ${ }^{2}$ that heavy working conditions in combination with a long workweek have the most detrimental effects, ${ }^{3}$ and that PIH mediates the above-stated associations methods.

\section{Study population}

Prospective data from a community cohort of pregnant women in the city of Amsterdam, the Netherlands, were used (Amsterdam Born Children and their Development (ABCD study)). The ABCD study investigates the relationship between maternal lifestyle and psychosocial conditions during pregnancy and the child's health at birth as well as in later life (www.abcdstudy.nl). ${ }^{28}$ Details of the study design, including measurements, have been described previously. ${ }^{28}{ }^{29}$ In short, between January 2003 and March 2004, all pregnant Amsterdam women were invited to participate at their first prenatal visit to the obstetric care provider (on average 12th gestational week), and requested to complete a questionnaire, covering socio-demographic data, obstetric history, lifestyle, dietary habits and psychosocial factors. The questionnaire was available in Dutch, English, Turkish and Arabic for immigrant women. Three months to 6 months after delivery, the women received an infant questionnaire covering the health of the mother and her baby.

In total 12373 women were invited and 8266 women returned the questionnaire (response rate: 67\%). Of this group, 7731 gave birth to a viable singleton infant for whom information on birth weight and pregnancy duration was available. For this study, we excluded births before 24 weeks of gestation and maternal age younger than 20 years. In total, 7561 women had complete data on all relevant variables for the analysis. The study protocol was approved by the medical ethical committees of all Amsterdam hospitals and the Registration Committee of Amsterdam. All participating women gave written consent.

\section{Measures}

Exposure measurement: employment was defined as paid work for at least 8 hours/week during first trimester (self-reported). All other situations were classified as being unemployed. The amount of weekly working hours was categorised into three categories (8-31 hours, 32-40 hours and $>40$ hours), based on conventional working schemes in the Netherlands. The self-administered validated Dutch version of the Job Content Questionnaire (JCQ) measured job strain. ${ }^{30} 31$ The JCQ consists of two subscales, "job demands' and 'job control', respectively, which together define 'job strain'. Job demand is covered by altogether 25 items, referring to work pace (11 items; concerning, eg, time pressure and amount of work), mental work load (7 items; eg, the requirement to perform simultaneously several tasks) and physical work load (7 items; concerning strenuous posture and load carrying). Job control is covered by 11 items, concerning, for example, perceived control of own work pace. All JCQ items use a 4-point response mode. In our study, scale reliability (Cronbach's $\alpha$ ) for job demands and job control were 0.82 and 0.91 , respectively. For analysis, the sum score of job demand was trichotomised into: low $(<50$ th percentile) moderate (between 50th and 90th percentile) and high ( $>90$ th percentile), and for job control: high ( $>50$ th percentile), moderate (between 10th and 50th percentile) and low ( $<10$ th percentile). Women with high job demands and low or moderate job control were scored as having high job strain, those with low job demands and moderate or high job control as having low job strain and all other combinations as having moderate job strain. ${ }^{29}$ Additional to the JCQ, physical work load was measured by ${ }^{1}$ the reported number of weekly hours standing or walking, categorised into 4 categories ( $<10$ hours, $10-19$ hours, $20-30$ hours and $>30$ hours), and ${ }^{2}$ by taking the subscale physical work load from the job demands scale as a separate variable. The score on this subscale was trichotomised into low $(<50$ th percentile), moderate (between 50th and 90th percentile) and high ( $>90$ th percentile).

Outcome measurement: pregnancy duration (ultrasound based or, if unavailable, on the timing of the last menstrual period) was obtained from the youth healthcare registration of the Public Health Service in Amsterdam; every newborn (alive or dead) is registered at the civil registration, and brought to the attention to the youth healthcare to be included in preventive schemes. The Dutch Perinatal Registration (PRN) provided comprehensive data on pregnancy, obstetric history and pregnancy outcomes for $80 \%$ of our sample. This data were linked by anonymous probabilistic linkage methods to the $\mathrm{ABCD}$ data, ${ }^{32}$ which also accounted for small errors on the birth date (eg, midnight births). If variables were available from two sources, for example, maternal age, this allowed for additional quality checks. 
Primary outcome variable was PTB (gestational age between 24 weeks and 37 weeks). The Dutch PRN registers the onset of delivery (eg, spontaneous, induction and section) only when women delivered under the supervision of a gynaecologist. Based on these data, we divided total PTB into spontaneous PTB (delivery onset by spontaneous preterm labour or premature rupture of membranes) and iatrogenic PTB (delivery onset through induction or primary caesarean section). PTBs with unknown type of delivery onset (11\%) were classified as spontaneous PTB if a women not specifically reported in the infant questionnaire to have had an iatrogenic delivery or if a women had not been under the supervision of a gynaecologist. ${ }^{23}$

Explanatory variables: apart from the above clinical information, all other explanatory variables were self-report: maternal age (years), parity (two categories: primiparae and multiparae), ethnicity (country of birth of the pregnant mother to include second generation: the Netherlands, Surinam/Antillean, Turkey/Morocco, other non-Western and other Western), maternal education (years of education after primary school, continuous), smoking during pregnancy (dichotomised into yes or no), alcohol use (dichotomised into yes or no), marital status (married/cohabiting vs single), previous PTB (dichotomised into yes or no) and pre-gravid maternal body mass index (BMI, $\mathrm{kg} / \mathrm{m}^{2}$ ). Chronic (pre-existent) and PIH were both defined combining self-reported data and PRN registration. Chronic hypertension was the case if pre-existent hypertension was recorded in the PRN or if women reported high blood pressure and/or the use of medication against high blood pressure before pregnancy or in the first 20 weeks of pregnancy. PIH was assumed to be present if pregnancy-related hypertension, eclampsia or pre-eclampsia was recorded in the PRN, or if women without pre-existent hypertension reported high blood pressure and/or the use of antihypertensive medication during pregnancy. ${ }^{33} 34$

\section{Statistical analysis}

We estimated the hypothesised effects of working conditions on PTB by logistic regression models in employed women only. First, univariate analysis for each working condition separately provided unadjusted effects. Multivariate models controlled for the following factors: maternal age, parity, educational level, smoking habits during pregnancy, pre-gravid BMI and previous PTB, to reveal the statistically independent effect of work conditions. These covariates were chosen as they previously proved to be independent risk factors for PTB. ${ }^{23}$ The correlations between the covariates were all below 0.23 (collinearity check). We tested if there was significant mediation by PIH (binary mediator) on the association between working conditions and PTB with structural equation modelling. A 95 percentile bootstrap CI was calculated based on 1000 bootstrap resamples for the indirect effect in order to test for significance. In all models, employed women with the least heavy working condition (lowest exposure category) were designated as the reference category, implying that risk estimates show added risk (if any) compared with low burden workers.

The combined effects of working hours and job strain and of working hours and physical work load were tested. Variables were redefined into six categories and the least heavy working condition in combination with a workweek of less than 32 hours was taken as the reference category. To test the modifying effect of hypertension, stratified analysis were performed for those with and without PIH.

Data were analysed using SPSS V.25.0. Goodness of fit of the logistic regression models was assessed by the Hosmer-Lemeshow test. The mediation analyses were conducted using the capture programme in Stata V.15. Only missing values of pre-pregnancy BMI were imputed (5\% missing); less than $1 \%$ of other data were missing.
Table 1 Maternal and infant characteristics by employment status, Amsterdam Born Children and their Development study, Amsterdam, the Netherlands, 2003-2004 ( $N=7561)$

\begin{tabular}{|c|c|c|}
\hline & Employed & Unemployed \\
\hline & $\mathrm{N}=4865$ & $\mathrm{~N}=2696$ \\
\hline & Mean (SD) or \% & Mean (SD) or \% \\
\hline Maternal age (years) & $31.8(4.3)$ & $29.7(5.5)$ \\
\hline Pre-pregnancy body mass index $\left(\mathrm{kg} / \mathrm{m}^{2}\right)$ & $22.8(3.5)$ & $23.9(4.6)$ \\
\hline Parity (\% primiparae) & 61.8 & 40.2 \\
\hline Education (years) & $9.9(3.4)$ & $6.6(4.3)$ \\
\hline Marital status (\% single) & 9.8 & 17.8 \\
\hline Smoked while pregnant (\% yes) & 8.4 & 10.6 \\
\hline Alcohol use while pregnant (\% yes) & 26.6 & 12.4 \\
\hline \multicolumn{3}{|l|}{ Ethnicity } \\
\hline Dutch & 68.4 & 26.9 \\
\hline Surinamese/Antillean & 7.3 & 11.4 \\
\hline Turkish/Moroccan & 5.5 & 29.4 \\
\hline Other Western & 4.2 & 21.4 \\
\hline Other non-Western & 14.6 & 10.8 \\
\hline \multicolumn{3}{|l|}{ Hypertensive disorder (\%) } \\
\hline No & 81.4 & 89.7 \\
\hline Pre-existent hypertension & 3.3 & 4.5 \\
\hline Pregnancy-induced hypertension & 15.3 & 5.4 \\
\hline Previous preterm birth (\% yes) & 0.8 & \\
\hline Gestational age (weeks) & $40.1(1.2)$ & $40.0(1.2)$ \\
\hline Birth weight (g) & $3510(483)$ & $3478(482)$ \\
\hline Gender of the baby (\% boys) & 50.1 & 50.7 \\
\hline Preterm birth (\% yes) & 5.2 & 5.7 \\
\hline
\end{tabular}

\section{RESULTS}

Compared with the non-response group ( $\mathrm{N}=4107)$, the response group $(\mathrm{N}=8266)$ was a little older (mean age: $31.7 \pm 5.2$ vs $30.2 \pm 5.8$ ), more often primiparae (\% primiparae: 55.7 vs 40.1 ), more often from Dutch origin (\% Dutch: 62.6 vs 35.3). No differences were found with respect to the outcome variables birth weight and pregnancy duration. To test whether selective participation caused selection bias, extensive non-response analysis was performed by probabilistic medical record linkage with the Dutch PRN. Results showed similar associations in the response and the non-response group between risk factors and several adverse outcome indicators, suggesting no selection bias. ${ }^{32}$

The socio-demographic background of the pregnant women, stratified by employment status, is shown in table 1 . Differences between the two groups can largely be explained by difference in employment status between the ethnic groups. Most of the women (63\%) worked at least 8 hours a week during first trimester. Employed compared with unemployed women were older, higher educated, smoked less, drunk more, had lower pre-gravid BMI and less often a previous PTB, had more often hypertensive disorders, were more often primiparae and less often single. Socio-demographic background, stratified by working condition, is shown in online supplemental table 1. High physical work load, long hours of standing/walking a week and high job strain were more prevalent in those women from lower educational or non-Dutch background. The rate of PTB in our sample (only singletons included) was $5.4 \%$. About $80 \%$ of the PTBs were spontaneous (table 2). This proportion did not differ between the employed and the unemployed women.

\section{Total PTB}

More than 30 hours/week standing/walking was associated with an increased risk for total PTB (OR: 1.44; 95\% CI: 1.01-2.24) in the adjusted analyses (table 3). A bias-corrected bootstrap CI for the 
Table 2 Prevalence of PTB according to employment status and working condition: Amsterdam Born Children and their Development study, Amsterdam, the Netherlands, 2003-2004 ( $N=7561)$

\begin{tabular}{|c|c|c|c|c|}
\hline & & PTB & PTB & PTB \\
\hline & Total N & $\begin{array}{l}\text { Total } \\
(\%)\end{array}$ & $\begin{array}{l}\text { Spontaneous } \\
(\%)\end{array}$ & $\begin{array}{l}\text { latrogenic } \\
(\%)\end{array}$ \\
\hline \multicolumn{5}{|c|}{ Weekly working hours } \\
\hline Unemployed & 2696 & 5.7 & 4.3 & 1.4 \\
\hline 8-31 (ref) & 1889 & 4.9 & 4.0 & 1.0 \\
\hline $32-40$ & 2676 & 5.5 & 4.4 & 1.0 \\
\hline$>40$ & 300 & 5.8 & 4.3 & 1.3 \\
\hline \multicolumn{5}{|c|}{ Weekly standing/walking hours } \\
\hline Unemployed & 2696 & 5.7 & 4.3 & 1.4 \\
\hline$<10$ (ref) & 2764 & 4.7 & 3.9 & 0.8 \\
\hline 10-19 & 1011 & 5.3 & 4.5 & 0.9 \\
\hline $20-30$ & 574 & 5.6 & 4.5 & 1.0 \\
\hline$>30$ & 356 & 8.4 & 5.9 & 2.5 \\
\hline \multicolumn{5}{|c|}{ Physical work load } \\
\hline Unemployed & 2696 & 5.7 & 4.3 & 1.4 \\
\hline Low (ref) & 2606 & 4.8 & 4.1 & 0.7 \\
\hline Moderate & 1692 & 5.9 & 4.5 & 1.4 \\
\hline High & 502 & 5.8 & 4.0 & 1.8 \\
\hline \multicolumn{5}{|l|}{ Job strain } \\
\hline Unemployed & 2696 & 5.7 & 4.3 & 1.4 \\
\hline Low (ref) & 2170 & 4.7 & 4.0 & 0.7 \\
\hline Moderate & 2152 & 5.7 & 4.4 & 1.3 \\
\hline High & 316 & 5.4 & 4.1 & 1.3 \\
\hline
\end{tabular}

Sample sizes differ slightly because of missing values.

PTB, preterm birth. indirect effect of standing/walking $>30$ hours/week on PTB (OR: 0.96; 95\% CI: 0.86-1.05) was not statistically significant, indicating no mediation by PIH (online supplemental table 2). Weekly working hours, physical workload and job strain were not associated with total PTB.

\section{Working conditions related to spontaneous versus iatrogenic PTB}

Working conditions were not associated with spontaneous PTB in the adjusted analysis. However, standing or walking for more than 30 hours/week was associated with increased risk for iatrogenic PTB. Adjusted OR was 2.09 (95\% CI: 1.00-4.97). A bias-corrected bootstrap CI for the indirect effect of standing/walking $>30$ hours a week on iatrogenic PTB (OR=0.78; 95\% CI: 0.45-1.35) was not statistically significant, indicating no mediation by PIH (online supplemental table 2). Other working conditions (weekly working hours, physical workload and job strain) were not associated with iatrogenic PTB after adjustments (table 3).

\section{Physical work load with weekly working hours as combined risk}

The combination of high physical work load with $\geq 32$ weekly working hours (4.7\% of the working women) was not associated with total or spontaneous PTB, yet it resulted in the highest risk for iatrogenic PTB (table 4). Compared with women with low physical workload who worked $<32$ hours/week (reference group), they showed a more than three times increased risk (adjusted OR: 3.42; 95\% CI: 1.04-8.21). The combination of high job strain with long working hours was not associated with an increased risk for PTB or any of its subtypes (data not shown).

Table 3 Univariate and multivariate effects of working conditions on PTB and its subtypes: ABCD study, Amsterdam, the Netherlands, 2003-2004 $(\mathrm{N}=7561)$

\begin{tabular}{|c|c|c|c|c|c|c|}
\hline & \multicolumn{2}{|l|}{ Total PTB } & \multicolumn{2}{|l|}{ Spontaneous PTB } & \multicolumn{2}{|l|}{ latrogenic PTB } \\
\hline & Crude & Adjusted* & Crude & Adjusted* & Crude & Adjustedt* \\
\hline & Or $(95 \% \mathrm{CI})$ & Or $(95 \% \mathrm{CI})$ & Or $(95 \% \mathrm{CI})$ & Or $(95 \% \mathrm{Cl})$ & Or $(95 \% \mathrm{Cl})$ & $\operatorname{Or}(95 \% \mathrm{Cl}$ \\
\hline \multicolumn{7}{|l|}{ Employed } \\
\hline Yes & 1.0 & 1.0 & 1.0 & 1.0 & 1.0 & 1.0 \\
\hline No & $1.07(0.87-1.32)$ & $1.06(0.83-1.36)$ & $1.01(0.80-1.27)$ & $0.98(0.74-1.30)$ & $1.32(0.86-2.03)$ & $1.39(0.89-2.31)$ \\
\hline \multicolumn{7}{|c|}{ Weekly working hourst } \\
\hline $8-31$ (ref) & 1.0 & 1.0 & 1.0 & 1.0 & 1.0 & 1.0 \\
\hline $32-40$ & $1.09(0.83-1.42)$ & $1.79(0.42-1.47)$ & $1.12(0.83-1.51)$ & $0.97(0.71-1.33)$ & $1.01(0.56-1.81)$ & $0.79(0.42-1.47)$ \\
\hline$>40$ & $1.15(0.67-3.95)$ & $1.3(0.8-2.3)$ & $1.11(0.61-2.02)$ & $0.95(0.51-1.78)$ & $1.33(0.45-3.93)$ & $1.15(0.37-3.55)$ \\
\hline \multicolumn{7}{|c|}{ Weekly standing/walking hourst } \\
\hline$<10$ (ref) & 1.0 & 1.0 & 1.0 & 1.0 & 1.0 & 1.0 \\
\hline $10-19$ & $1.14(0.82-1.58)$ & $1.10(0.79-1.53)$ & $1.16(0.81-1.65)$ & $1.11(0.77-1.59)$ & $1.08(0.50-2.33)$ & $1.07(0.49-2.34)$ \\
\hline $20-30$ & $1.21(0.81-1.79)$ & $1.08(0.72-1.62)$ & $1.19(0.77-1.84)$ & $1.08(0.69-1.69)$ & $1.28(0.52-3.15)$ & $1.12(0.45-2.81)$ \\
\hline$>30$ & $1.80(1.19-2.74)$ & $1.44(1.01-2.24)$ & $1.58(1.00-2.56)$ & $1.30(0.78-2.16)$ & $2.81(1.25-6.33)$ & $2.09(1.00-4.97)$ \\
\hline \multicolumn{7}{|c|}{ Physical work loadt } \\
\hline Low (ref) & 1.0 & 1.0 & 1.0 & 1.0 & 1.0 & 1.0 \\
\hline Moderate & $1.23(0.93-1.61)$ & $1.11(0.84-1.48)$ & $1.11(0.82-1.50)$ & $1.01(0.74-1.39)$ & $1.89(1.03-3.48)$ & $1.66(0.88-3.13)$ \\
\hline High & $1.18(0.78-1.81)$ & $0.95(0.60-1.50)$ & $1.00(0.61-1.63)$ & $0.81(0.48-1.37)$ & $2.23(1.01-5.11)$ & $1.68(0.67-4.22)$ \\
\hline \multicolumn{7}{|l|}{ Job straint } \\
\hline Low (ref) & 1.0 & 1.0 & 1.0 & 1.0 & 1.0 & 1.0 \\
\hline Moderate & $1.20(0.92-1.57)$ & $1.18(0.90-1.55)$ & $1.11(0.83-1.49)$ & $1.09(0.81-1.47)$ & $1.70(0.93-3.13)$ & $1.65(0.89-3.05)$ \\
\hline High & $1.14(0.68-1.93)$ & $1.02(0.60-1.76)$ & $1.04(0.57-1.88)$ & $0.96(0.52-1.77)$ & $1.71(0.57-5.11)$ & $1.37(0.44-4.27)$ \\
\hline
\end{tabular}

Goodness of fit tests showed no evidence of lack of fit ( $p>0.0 .07$ for the three adjusted logistic models).

Bold values indicate statistically significance at the level of $p<0.05$.

*Model adjusted for: parity, smoking, previous PTB, ethnicity, maternal educational level, maternal age and maternal pre-pregnancy BMI.

tOnly employed women included (paid work for at least 8 hours/week, $\mathrm{N}=4865$ ).

.ABCD, Amsterdam Born Children and their Development; BMI, body mass index; PTB, preterm birth. 
Table 4 Results of the combined exposure of weekly working hours and physical work load on iatrogenic PTB in employed women only (N=4865)

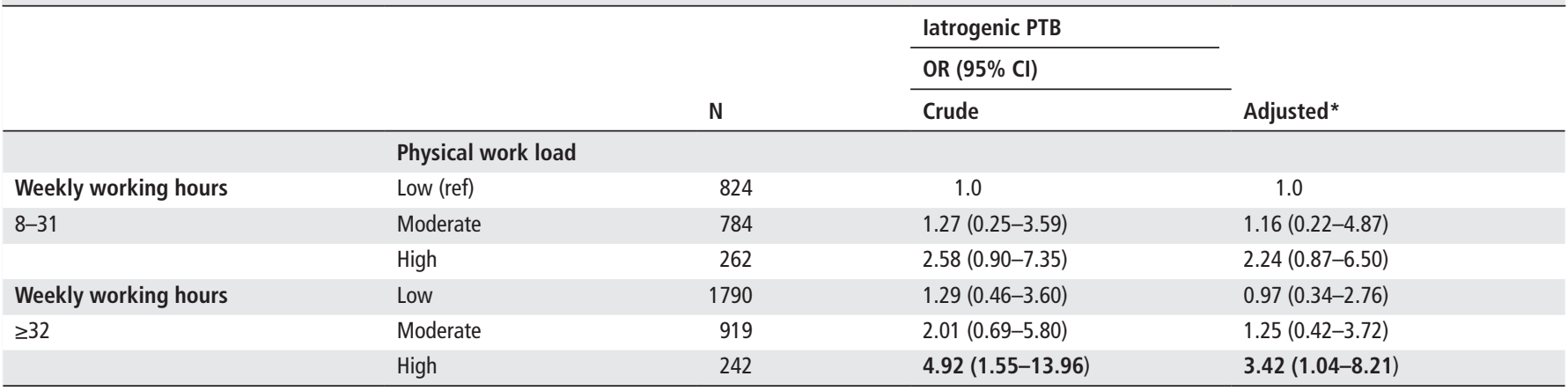

Goodness of fit tests showed no evidence of lack of fit ( $p>0.40$ for the adjusted logistic model).

Bold values indicate statistically significance at the level of $p<0.05$.

*Model adjusted for: parity, smoking, previous PTB, ethnicity, maternal educational level, maternal age and maternal pre-pregnancy BMI.

BMI, body mass index; PTB, preterm birth.

\section{Modifying role of PIH}

The relation between physical work load and iatrogenic PTB was modified by PIH ( $\mathrm{p}$ for interaction $=0.07$; table 5 ). The analysis shows that high physical work load in combination with PIH was related to iatrogenic PTB. This modifying effect was not present for total PTB and spontaneous PTB (data not shown).

\section{DISCUSSION}

In this large prospective community cohort of pregnant women, high physical work load and more than 30 hours/week standing or walking, measured during women's first trimester, were independently associated with a higher risk for iatrogenic PTB. The combination of high physical work load and a long workweek showed the highest impact, with (after adjustment) a more than three times increased risk for iatrogenic PTB. On the other hand, no effects of work were found for spontaneous PTB. In general, PTB effects were smaller than those observed for a small for gestational age (SGA. ${ }^{29}$

Our results suggests that high physical work load does not lead to a more severe outcome via the development of PIH (no mediation). This supports previous findings that high physical work load was not associated with the risk of PIH, or its subcomponents preeclampsia or gestational hypertension. ${ }^{1735}$ In fact, the results suggest that physical work load has a more severe impact on the pregnancy outcome when PIH is present ('risk-enhancer'). Indeed, in another paper of our group, we showed that high physical work load, combined with a long workweek is associated with reduced fetal growth. ${ }^{29}$ In this paper, we did not combine physical work load with hypertension, but the prevalence of an SGA baby in those with gestational hypertension was $22.5 \%$ when this was combined with high physical work load, while this was $13.6 \%$ in those with low physical work load. It is known that pre-eclampsia, fetal distress, SGA and placental abruption are indicators for a iatrogenic PTB, which suggests an association with ischaemic placental disease. ${ }^{36}$ It could be that those women who develop hypertension during pregnancy continue to work in this adverse work situation, but also that the origin of a suboptimal placentation during the first weeks of pregnancy is caused by high physical work load in combination with other factors (eg, genetic or environmental) that predispose for the developing of high blood pressure. Regrettably, we only have the work exposure variables during the first trimester, whether women changed their working conditions, is not known.

Our results confirm the case-control study from Escribá-Agüir and co-workers, ${ }^{37}$ who reported that the magnitude of the physical work load was greater for iatrogenic PTB (OR: 3.88; 95\% CI: 2.04-7.39) than for spontaneous PTB (OR: 1.74; 95\% CI: 0.993.01 ), and the study from Klebanov in which they compared the pregnancy outcome from medical residents to those from the wives

Table 5 Relation between physical work load, weekly hours standing/walking and iatrogenic PTB stratified by hypertensive status in employed women only $(n=4865)$

\begin{tabular}{|c|c|c|c|c|}
\hline & & \multirow[b]{3}{*}{$\mathbf{N}$} & latrogenic PTB & \multirow[b]{3}{*}{ Adjusted* } \\
\hline & & & OR $(95 \% \mathrm{Cl})$ & \\
\hline & & & Crude & \\
\hline & \multicolumn{4}{|c|}{ Physical work load } \\
\hline Hypertension during pregnancy & Low (ref) & 2124 & 1.0 & 1.0 \\
\hline \multirow[t]{2}{*}{ No } & Moderate & 1370 & $1.92(0.79-4.64)$ & $1.74(0.69-4.38)$ \\
\hline & High & 415 & $1.15(0.23-5.32)$ & $1.10(0.22-5.55)$ \\
\hline \multirow[t]{3}{*}{ Pre-existent hypertension } & Low & 79 & 1.0 & 1.0 \\
\hline & Moderate & 54 & $0.76(0.28-3.17)$ & $0.75(0.14-4.12)$ \\
\hline & High & 25 & $1.08(0.20-5.77)$ & $0.94(0.12-7.34)$ \\
\hline \multirow[t]{3}{*}{$\mathrm{PIH}$} & Low & 403 & 1.0 & 1.0 \\
\hline & Moderate & 268 & $3.46(1.05-11.36)$ & $3.25(0.96-10.98)$ \\
\hline & High & 62 & 7.09 (1.72-29.19) & $6.44(1.21-29.76)$ \\
\hline
\end{tabular}

Goodness of fit tests showed no evidence of lack of fit ( $p>0.51$ for the adjusted logistic model).

Bold values indicate statistically significance at the level of $p<0.05$.

*Model adjusted for: parity, smoking, previous PTB, ethnicity, maternal educational level, maternal age and maternal pre-pregnancy BMI.

BMI, body mass index; PIH, pregnancy-induced hypertension; PTB, preterm birth. 
of male medical residence. They found no difference in the rate of preterm delivery; however, (pre)eclampsia, a major risk factor for iatrogenic PTB, was more than twice as common among the residents, after adjustment for parity, age and ethnicity. ${ }^{16}$ Escribá-Agüir and co-workers also combined the two subtypes (total PTB) and showed an increased risk of physical work load (OR: 2.35; 95\% CI: 1.41-3.94), which is also previously found but not confirmed in our study. The systematic reviews of Cai et al, Bonzini et al and van Beukering et al concluded consistent findings between prolonged working hours, prolonged standing and walking and physical work load on preterm delivery. Some larger, prospective studies, as those from Ceron-Mireles (high job strain, weekly working hours, hours standing and physical effort) and from Tuntiseranee et al (Karasek et al's physical job demands scale) do not find any effect on total PTB. ${ }^{38} 39$

We did not find any effect of job strain (work stress) on preterm delivery. This is in agreement with a large prospective cohort study in the USA. ${ }^{12}$ In another population based case-control study, ${ }^{10}$ an effect was found for low job satisfaction. Our results did not show an effect of job strain on total preterm delivery or the subtypes. Also in combination with full-time working, job strain did not result in any increased risk, comparable to others. ${ }^{27}$ An association might be present in subgroups like those with low social support or in specific ethnic groups. ${ }^{22}$

\section{Potential limitations}

Our study involved several limitations. First, as stated above, we measured working conditions only during the first trimester. Whether working conditions changed during pregnancy is unknown; it is, therefore, possible that first trimester is an indicator for third trimester working conditions. Changes during pregnancy were most likely in the highest work exposure groups ${ }^{40}$ (eg, women with highly physical workloads may have moved to a desk job). Such attenuations in exposure would imply that our estimates are conservative. Some studies have included multiple measurements during pregnancy but have restricted analyses to women who worked throughout their pregnancy. ${ }^{41}$ This approach leads to underestimates of early-pregnancy workload effects, and may even result in favourable rather than adverse work effects among those who work to term, if early quitting is associated with work-related pregnancy complications such as suspected intrauterine growth restriction.

Second, the percentage of unemployment was high in our cohort (36\%). This can be explained in part by our definition of employment as working at least 8 hours/week during the first trimester. Given that most studies include only working women, comparisons between previous studies and our investigation are difficult. However, the unemployment rate in the Netherlands among women in the 25-34 year age group is $24.7 \%$, which is high relative to other Western countries. In our cohort, the percentage was higher than the norm as a result of the comparatively large group of women of nonDutch origin, among whom, according to national statistics, rates of unemployment are often high. We believe that our employment rate was representative of large cities in the Netherlands and that selective participation among women who were unemployed did not occur.

Third, we showed that adverse working conditions are indicative of lower socioeconomic status (SES) (online supplemental table 1), which in itself is associated with iatrogenic PTB. ${ }^{6}$ Although education, profession and income are all components of SES, many studies focusing on community populations indicate that the main effects of SES act through employment (in addition to smoking) and, to a lesser extent, education. We adjusted for educational level, which can be considered as overcorrection; the true estimates might, therefore, be larger.
Fourth, despite our large cohort, the numbers are small for the iatrogenic PTB. Therefore, the results should be interpreted with caution. The postulated role of gestational hypertension should be confirmed in future studies.

Fifth, despite our efforts to include all pregnant women in Amsterdam, selective participation took place and those from ethnic minorities and lower socioeconomic status were less presented in our study. ${ }^{28} 29$ However, we think that this did not lead to biased results as the included groups were representative for the total groups. ${ }^{32}$ However, this selective participation might have influenced the prevalence of the working conditions. Recall bias is unlikely as the information on working conditions were obtained before the outcome was assessed.

\section{Study implications}

In conclusion, we found that in general there is no reason to assume that working during pregnancy has a negative influence on preterm delivery, or its subtypes. However, the association observed between iatrogenic PTB and high physical work load in combination with a long workweek seems to be genuine. In addition, high physical work load should be avoided in those pregnant women with first indications of hypertensive disorders during pregnancy.

We believe that optimising the work environment during pregnancy is important as the participation of women of reproductive age in the workforce continues to increase. Although only $4.7 \%$ of the working women in our cohort were in the highest physical work load group and longest workweek categories, women facing such conditions should not be ignored given that these percentages will be higher in other countries in which part-time employment is less common. Moreover, these adverse working conditions were more prevalent in women from lower socioeconomic and non-Dutch background. As these women also have other risk factors for PTB, like smoking, these groups might need specific attention in preventive strategies.

We are aware that our results must be confirmed in other large scaled prospective community cohort studies before firm conclusions can be drawn. These studies should include large numbers of pregnant women to validly study work-related risk factors for iatrogenic PTB and the role of hypertensive disorders. Multiple measurements of these work-related risk factors should be included in future studies to investigate whether the first trimester is a vulnerable window in which work-related risk factors can cause pregnancy complications that cannot be reversed. Although most pregnant women reduce their working loads at the end of their pregnancy, our results indicate that reducing physical workload in the initial stages of pregnancy may be beneficial among women with full-time physical demanding work and first signs of hypertensive disorders.

Acknowledgements We are grateful to all participating hospitals, obstetric clinics and general practitioners for their assistance in the implementation of the Amsterdam Born Children and their Development study. We like to thank all the participated pregnant women for their cooperation. We thank MW Harskamp-van Ginkel for her statistical advice.

Contributors All the authors contributed to the conceptualisation and the writing of the manuscript. TV conducted the analyses and drafted the manuscript; TV and $G B$ were project managers of the Amsterdam Born Children and their Development study and were involved in obtaining the data. GB and TB provided advice on the analyses and interpretation of the data, revised the draft versions and approved the final version of the manuscript.

Funding Financial support for the Amsterdam Born Children and their Development study was granted by the Netherlands Organisation for Health Research and Development (ZonMw), the Hague, the Public Health Service and Municipal Council of Amsterdam and the Amsterdam UMC

Competing interests None declared. 
Patient consent for publication Not required.

Ethics approval Approval for the Amsterdam Born Children and their Development study was obtained from the Central Committee on Research Involving Human Subjects (CCMO number P02.0335L, 2002), the Medical Ethical Committees of participating hospitals and the Registration Committee of Amsterdam.

Provenance and peer review Not commissioned; externally peer reviewed.

Data availability statement Data are available upon request due to ethical restrictions related to protecting patient confidentiality. Researchers who are interested in using data for research purposes can apply for access to the Amsterdam Born Children and their Development data by contacting the research committee at abcd@amc.uva.n.

Supplemental material This content has been supplied by the author(s). It has not been vetted by BMJ Publishing Group Limited (BMJ) and may not have been peer-reviewed. Any opinions or recommendations discussed are solely those of the author(s) and are not endorsed by BMJ. BMJ disclaims all liability and responsibility arising from any reliance placed on the content. Where the content includes any translated material, BMJ does not warrant the accuracy and reliability of the translations (including but not limited to local regulations, clinical guidelines, terminology, drug names and drug dosages), and is not responsible for any error and/or omissions arising from translation and adaptation or otherwise.

Open access This is an open access article distributed in accordance with the Creative Commons Attribution Non Commercial (CC BY-NC 4.0) license, which permits others to distribute, remix, adapt, build upon this work non-commercially, and license their derivative works on different terms, provided the original work is properly cited, appropriate credit is given, any changes made indicated, and the use is non-commercial. See: http://creativecommons.org/licenses/by-nc/4.0/.

ORCID iD

Tanja Vrijkotte http://orcid.org/0000-0003-3641-4048

\section{REFERENCES}

1 Saigal S, Doyle LW. An overview of mortality and sequelae of preterm birth from infancy to adulthood. Lancet 2008;371:261-9.

2 Medley N, Poljak B, Mammarella S, et al. Clinical guidelines for prevention and management of preterm birth: a systematic review. BJOG 2018;125:1361-9.

3 van Zijl MD, Koullali B, Oudijk MA, et al. Trends in preterm birth in singleton and multiple gestations in the Netherlands 2008-2015: a population-based study. Eur J Obstet Gynecol Reprod Biol 2020;247:111-5.

4 Savitz DA, Murnane P. Behavioral influences on preterm birth: a review. Epidemiology 2010;21:291-9.

5 Goldenberg RL, Culhane JF, lams JD, et al. Epidemiology and causes of preterm birth. Lancet 2008:371:75-84.

6 Ruiz M, Goldblatt P, Morrison J, et al. Mother's education and the risk of preterm and small for gestational age birth: a drivers meta-analysis of 12 European cohorts. $J$ Epidemiol Community Health 2015;69:826-33.

7 Savitz DA, Olshan AF, Gallagher K. Maternal occupation and pregnancy outcome. Epidemiology 1996;7:269-74.

8 Jansen PW, Tiemeier $\mathrm{H}$, Verhulst FC, et al. Employment status and the risk of pregnancy complications: the generation R study. Occup Environ Med 2010:67:387-94

9 Cai C, Vandermeer B, Khurana R, et al. The impact of occupational shift work and working hours during pregnancy on health outcomes: a systematic review and metaanalysis. Am J Obstet Gynecol 2019;221:563-76.

10 Saurel-Cubizolles MJ, Zeitlin J, Lelong N, et al. Employment, working conditions, and preterm birth: results from the Europop case-control survey. J Epidemiol Community Health 2004;58:395-401.

11 Snijder CA, Brand T, Jaddoe V, et al. Physically demanding work, fetal growth and the risk of adverse birth outcomes. the generation R study. Occup Environ Med 2012:69:543-50.

12 Lee LJ, Symanski E, Lupo PJ, et al. Role of maternal occupational physical activity and psychosocial stressors on adverse birth outcomes. Occup Environ Med 2017;74:192-9

13 Magann EF, Evans SF, Chauhan SP, et al. The effects of standing, lifting and noise exposure on preterm birth, growth restriction, and perinatal death in healthy low-risk working military women. J Matern Fetal Neonatal Med 2005;18:155-62.

14 Pompeii LA, Savitz DA, Evenson KR, et al. Physical exertion at work and the risk of preterm delivery and small-for-gestational-age birth. Obstet Gynecol 2005:106:1279-88.
15 Brett KM, Strogatz DS, Savitz DA. Employment, job strain, and preterm delivery among women in North Carolina. Am J Public Health 1997;87:199-204.

16 Klebanoff MA, Shiono PH, Rhoads GG. Outcomes of pregnancy in a national sample of resident physicians. N Eng/ J Med 1990;323:1040-5.

17 Bonzini M, Coggon D, Palmer KT. Risk of prematurity, low birthweight and preeclampsia in relation to working hours and physical activities: a systematic review. Occup Environ Med 2007;64:228-43.

18 Mozurkewich EL, Luke B, Avni M, et al. Working conditions and adverse pregnancy outcome: a meta-analysis. Obstet Gynecol 2000;95:623-35.

19 van Beukering MDM, van Melick MJGJ, Mol BW, et al. Physically demanding work and preterm delivery: a systematic review and meta-analysis. Int Arch Occup Environ Health 2014;87:809-34.

20 Croteau A. Occupational lifting and adverse pregnancy outcome: a systematic review and meta-analysis. Occup Environ Med 2020;77:496-505.

21 Cai C, Vandermeer B, Khurana R, et al. The impact of occupational activities during pregnancy on pregnancy outcomes: a systematic review and metaanalysis. Am J Obstet Gynecol 2020;222:224-38.

22 Mutambudzi M, Meyer JD, Warren N, et al. Effects of psychosocial characteristics of work on pregnancy outcomes: a critical review. Women Health 2011:51:279-97.

23 Goedhart $\mathrm{G}$, van Eijsden $\mathrm{M}$, van der Wal MF, et al. Ethnic differences in preterm birth and its subtypes: the effect of a cumulative risk profile. BJOG 2008;115:710-9.

24 Bonzini M, Coggon D, Godfrey K, et al. Occupational physical activities, working hours and outcome of pregnancy: findings from the Southampton women's survey. Occup Environ Med 2009;66:685-90

25 Trudel X, Brisson C, Gilbert-Ouimet M, et al. Psychosocial stressors at work and ambulatory blood pressure. Curr Cardiol Rep 2018;20:127.

26 Meyer JD, Muntaner C, O'Campo P, et al. Longitudinal assessment of Effort-Reward imbalance and job strain across pregnancy: a preliminary study. Matern Child Health 」 2016;20:1366-74.

27 Sejbaek CS, Bay H, Larsen AD, et al. Combined exposure to lifting and psychosocial strain at work and adverse pregnancy outcomes-A study in the Danish national birth cohort. PLoS One 2018:13:e201842.

28 van Eijsden M, Vrijkotte TGM, Gemke RJBJ, et al. Cohort profile: the Amsterdam born children and their development (ABCD) study. Int J Epidemiol 2011:40:1176-86.

29 Vrijkotte TGM, van der Wal MF, van Eijsden M, et al. First-Trimester working conditions and birthweight: a prospective cohort study. Am J Public Health 2009;99:1409-16.

30 Choi B, Bjorner JB, Ostergren P-O, et al. Cross-language differential item functioning of the job content questionnaire among European countries: the JACE study. Int J Behav Med 2009;16:136-47.

31 Karasek R, Brisson C, Kawakami N, et al. The job content questionnaire (JCQ): an instrument for internationally comparative assessments of psychosocial job characteristics. J Occup Health Psychol 1998;3:322-55.

32 Tromp M, van Eijsden M, Ravelli ACJ, et al. Anonymous non-response analysis in the $A B C D$ cohort study enabled by probabilistic record linkage. Paediatr Perinat Epidemiol 2009;23:264-72.

33 Oostvogels AJJM, Busschers WB, Spierings EJM, et al. Pre-pregnancy weight status, early pregnancy lipid profile and blood pressure course during pregnancy: the $A B C D$ study. PLoS One 2017;12:e0177554.

34 Vollebregt KC, van der Wal MF, Wolf $\mathrm{H}$, et al. Is psychosocial stress in first ongoing pregnancies associated with pre-eclampsia and gestational hypertension? BJOG 2008:115:607-15

35 Nugteren JJ, Snijder CA, Hofman A, et al. Work-Related maternal risk factors and the risk of pregnancy induced hypertension and preeclampsia during pregnancy. the generation R study. PLoS One 2012;7:e39263.

36 Vahanian SA, Lavery JA, Ananth CV, et al. Placental implantation abnormalities and risk of preterm delivery: a systematic review and metaanalysis. Am I Obstet Gynecol 2015;213:S78-90

37 Escribá-Agüir V, Perez-Hoyos S, Saurel-Cubizolles MJ. Physical load and psychological demand at work during pregnancy and preterm birth. Int Arch Occup Environ Health 2001:74:583-8.

38 Cerón-Mireles P, Harlow SD, Sánchez-Carrillo CI. The risk of prematurity and small-forgestational-age birth in Mexico City: the effects of working conditions and antenatal leave. Am J Public Health 1996;86:825-31.

39 Tuntiseranee P, Geater A, Chongsuvivatwong V, et al. The effect of heavy maternal workload on fetal growth retardation and preterm delivery. A study among southern Thai women. J Occup Environ Med 1998;40:1013-21.

40 Croteau A, Marcoux S, Brisson C. Work activity in pregnancy, preventive measures, and the risk of preterm delivery. Am J Epidemiol 2007:166:951-65.

41 Marbury MC. Relationship of ergonomic stressors to birthweight and gestational age. Scand J Work Environ Health 1992:18:73-83. 